\title{
AKUNTANSI PENJUALAN KONSINYASI PADA TOKO ASRIF JATI CURUP
}

\author{
Tuti Hermelinda ${ }^{1}$ \\ Politeknik Raflesia Rejang Lebong \\ Email : tutihermelinda.polraf@gmail.com ${ }^{1}$
}

\begin{abstract}
ABSTRAK
Penelitian ini menggunakan metode analisis deskriptif yaitu penerapan akuntansi konsinyasi pada Toko Asrif Jati Curup dengan menggunakan metode terpisah dan tidak terpisah. Dalam akuntansi konsinyasi ini pihak toko Asrif jati bertindak sebagai consignee/ pihak yang menerima titipan barang dari PT Jati Jepara. Pada penelitian ini digunakan metode pencatatan akuntansi konsinyasi pada toko Asrif Jati dengan menggunakan metode terpisah dan tidak terpisah Penelitian dilakukan dengan mengadakan observasi langsung dan wawancara guna mendapatkan data yang diperlukan. Dari hasil analisis diperoleh hasil penjualan bulan Januari sebesar Rp. 58.000.000 dengan komisi untuk toko Asrif Jati sebagai consignee sebesar Rp. 5.800.000 dan jumlah uang yang disetor kepada PT Jati Jepara adalah sebesar Rp. 50.700.000, Penjualan bulan Februari sebesar Rp. 56.600.000 dengan komisi untuk toko Asrif Jati sebagai consignee sebesar Rp. 5.660.000 dan jumlah uang yang disetor kepada PT Jati Jepara adalah sebesar Rp. 50.700.000 dan Penjualan bulan Maret sebesar Rp. 114.950.000 dengan komisi untuk toko Asrif Jati sebagai consignee sebesar Rp. 11.495.000 dan jumlah uang yang disetor kepada PT Jati Jepara adalah sebesar Rp. 103.200.000.
\end{abstract}

\section{Kata Kunci : Akuntansi Konsinyasi, Metode Terpisah dan Tidak Terpisah}

\section{ABSTRACT}

This research uses descriptive analysis method, which describes the calculation of consignment sales at Asrif Jati Curup Shop using a separate and inseparable method. In this consignment accounting, the teak Asrif shop acts as the consignee / party receiving goods from PT Jati Jepara. In this study analyzed how journals and calculations carried out by the Asrif Jati shop using separate and inseparable methods. Research was conducted by conducting direct observation and interviews in order to obtain the required data. From the analysis, it was found that the sales in January were Rp. 58,000,000 with a commission for the Asrif Jati shop as a consignee of Rp. 5,800,000 and the amount of money paid to PT Jati Jepara is Rp. 50,700,000, sales in February of Rp. 56,600,000 with a commission for the Asrif Jati shop as a consignee of Rp. 5,660,000 and the amount of money paid to PT Jati Jepara was Rp. 50,700,000 and sales in March of Rp. 114,950,000 with a commission for the Asrif Jati shop as a consignee of Rp. 11,495,000 and the amount of money that was paid to PT Jati Jepara was Rp. 103,200,000.

Keywords: Consignment Analysis, Separate and Undivided Methods 


\section{PENDAHULUAN}

Penjualan konsinyasi banyak diminati karena penjualan konsinyasi memiliki manfaat baik bagi pengamat maupun komisioner. Perusahaan retail seringkali keberatan jika harus membeli langung dari perusahaan. Penyebabnya seperti keterbatasan modal dan resiko besar yang harus ditanggung jika barang yang usdah mereka beli kurang laku dipasaran. Selain itu hal ini juga merupakan strategi perusahaan untuk menjaga kesimbangan jumlah barang yang ada dipasaran, yang tentunya diharapkan supaya pembeli mudah mencari produk dipasaran. Saat ini penjualan konsinyasi merupakan salah satu jenis penjualan yang digunakan oleh perusahaan-perusahaan dalam kegiatan untuk memperluas daerah pemasaran. Penjualan konsinyasi merupakan pengiriman atau penitipan barang dari pemilik kepada pihak lain yang bertindak sebagai agen penjualan. Pemilik barang disebut dengan pengamat dan pihak yang dititipkan barang tersebut disebut dengan komisioner.

Menurut Halim (2015: 65), Konsinyasi adalah penjualan dengan perjanjian, dimana pihak pemilik barang/consignor/pengamanat menyerahkan barangnya kepada pihak lain, yaitu consignee/komisioner untuk dijual kepada pihak luar dan pihak consignee mendapatkan sejumlah komisi dari pihak consignor. Menurut Yunus dan Harnanto (2013: 141), Konsinyasi adalah suatu perjanjian dimana salah satu pihak yang memiliki barang menyerahkan sejumlah barang tertentu untuk dijualkan dengan memberikan komisi (tertentu). Sedangkan menurut Maria (2011: 16), Konsinyasi adalah pihak yang memiliki barang menitipkan barangnya kepada pihak lain untuk dijualkan dengan adanya perjanjian tertentu.

Penjualan yang dilakukan dengan cara konsinyasi akan lebih memudahkan perusahaan dalam memasarkan produknya. Hal tersebut dikarenakan dengan melakukan penjualan secara konsinyasi banyak pihak yang akan menjadi mitra perusahaan. Dengan demikian daerah-daerah yang menjadi tujuan pemasaran perusahaan akan lebih muda terjangkau, karena telah memiliki mitra kerja sama untuk memasarkan produk-produk perusahaan tersebut. Dalam hal metode pencatatan atas transaksi penjualan konsinyasi terdapat prosedur-prosedur pembukuan tersendiri yang biasanya diikuti oleh pihak komisioner. Pada prinsipnya pendapatan dalam konsinyasi diakui pada saat penjualan terhadap barang-barang konsinyasi diakui oleh komisioner pada pihak ketiga. Jika pengamanat membutuhkan laporan penjualan atas penjualan barang-barang konsinyasi, maka pencatatan harus diselenggarakan secara terpisah dari transaksi penjualan reguler.

Toko Asrif Jati Curup adalah perusahaan yang bergerak dibidang pemasaran kayu Jati Jepara. Toko Asrif Jati Curup beralamat di Jl.MH.Thamrin kelurahan Air Rambai Kecamatan Curup yang merupakan salah satu perusahaan yang melakukan penjualan secara konsinyasi. Hal ini dilakukan guna memperluas dan memperkenalkan produk yang baru dikenal. Dalam kegiatan operasionalnya Toko Asrif Jati Curup mendapatkan barang dari PT Jati Jepara. Secara teknisnya belum ada pencatatan yang sesuai prosedur konsinyasi antara PT Jati Jepara dengan Toko Asrif Jati. Selama ini sistem penjualan antara kedua pihak hanya berdasarkan kepercayaan saja. Hal ini tentu tidak dibenarkan dalam pencatatan akuntansi, karena dalam akuntansi konsinyasi akan dihitung besarnya komisi yang didapat dari pihak yang dititipkan barang dagangan(Consignee) ,sehingga diperlukan pencatatan yang benar dan akurat agar tidak ada pihak yang merasa dirugikan. 


\section{TINJAUAN LITERATUR}

\section{Pengertian Penjualan Konsinyasi}

Menurut Maria Simamora (2015), Penjualan konsinyasi melibatkan dua pihak yaitu pihak yang memiliki barang disebut consignor (pengamat) dan pihak yang mengesahkan penjualan barang disebut consignee (komisioner). Menurut Darsono (2014), Konsinyasi dapat diartikan sebagai penjualan dengan pemilik menitipkan barang kepada pihak lain untuk menjualkan dengan harga dan syarat yang telah diatur dalam perjanjian. Menurut Hidayat (2012), konsinyasi adalah suatu perjanjian dimana salah satu pihak yang memiliki barang menyerahkan sejumlah barang kepada pihak tertentu. Pemilik barang yang menitipkan barang disebut cosignor (pengamat), sementara pihak yang dititipkan barang disebut consignee (komisioner). Menurut Afriyanto (2014), penjualan konsinyasi adalah suatu perjanjian antara pemilik barang dengan pihak lain untuk menjualkan barangnya dengan pemberian komisi tertentu. Menurut Afriyanto (2014), pihak-pihak yang terlibat dalam konsinyasi adalah:

a. Pengamat (consignor) adalah pihak yang menitipkan barang atau pemilik barang. Pemngamat akan tetap mencatat barang yang dititipkannya sebagai persediaan selama barang yang dititipkan belum terjual atau menungu laporan dari komisioner.

b. Komisioner (consignee) adalah pihak yang menerima titipan barang penjualan konsinyasi dalam pengertian sehari-hari dikenal dengan sebutan penjualan dengan cara penitipan.

Menurut Pujianto (2012) metode konsinyasi merupakan metode titip jual artinya pengamat menitipkan barang kepada komisioner dan bila barang laku maka pihak komisioner baru membayarnya. Model penjualan konsinyasi ini merupakan salah satu tren yang sedang berkembang. Salah satu keuntungan metode ini oleh komisioner adalah komisioner hanya menyediakan tempat untuk menampilkan barang yang dijual dan hanya membayar barang bila barang tersebut terjual. Sedangkan keuntungan metode ini untuk pengamat adalah pengamat dapat mengetahui mengetahui sejumlah barang-barang yang dijual oleh komisioner oleh masyarakat.

Terdapat beberapa alasan bagi consignor maupun consignee untuk memilih perdagangan secara konsinyasi, antara lain:

1. Bagi Pihak Consignor

a) Barang itu merupakan barang yang baru diproduksi dan permintaan akan peroduk ini tidak diketahui dan tidak pasti.

b) Penjualan diwaktu lalu terbukti tidak menguntungkan bagi agen penjual.

c) Barang itu mahal, dan membutuhkan investasi yang besar bagi agen penjual jika harus membelinya.

d) Fluktuasi harga atau produk ini tidak tahan lama sehingga agen penjual setuju membeli barang jika hanya resiko kerugian ditanggung oleh pihak lain. Agen enjual, yang tidak memikul kewajiban dan tidak pula menanggung resiko, pada umumnya bersedia menerima barang atas dasar konsinyasi meskipun mungkin ia tidak bersedia membelinya.

e) Konsinyor dapat memperoleh spesialis penjualan.

f) Harga jual ecer barang konsinyasi dapat dikendalikan oleh pihak konsinyor yang masih jadi pemilik barang ini. Pengendalian ini sulit atau bahkan tidak mungkin dilakukan apabila barang ini dijual kepada agen penjual. 


\section{Bagi Pihak Consignee (komisioner)}

a) Pihak konsinyasi terlepas dari kegagalan menjual barang itu atau dari resiko penjualan dengan rugi. Faktor ini sangat penting terutama untuk produk baru atau produk yang untuk pertama kalinya dijual di suatu daerah tertentu.

b) Risiko kerusakan fisik dan fluktuasi harga dapat dihindari. Kedua macam pertimbangan ini penting artinya terutama dalam perdagangan ternak, hasil bumi, dan produk lainnya yang cepat rusak.

c) Kebutuhan modal kerja berkurang, karena penetapan harga pokok persediaan barang konsinyasi dilakukan dilakukan oleh pihak konsinyor. (Allan R.Drebin, 2010:158-159)

\section{Akuntansi Penjualan Konsinyasi}

Metode pencatatan yang dapat dipakai baik oleh pengamanat (consignor) maupun komisioner (consignee) ada dua, yaitu:

a. Metode Terpisah Dalam metode terpisah laba atau rugi dari penjualan konsinyasi disajikan secara terpisah dengan laba atau rugi penjualan biasa atau penjualan lainnya. Hal ini dilakukan dengan tujuan agar pada akhir periode dapat diketahui berapa laba atau rugi yang diperoleh dari penjualan konsinyasi dan berapa laba atau rugi yang diperoleh dari penjualan lainnya.

b. Metode Tidak Terpisah Dalam metode tidak terpisah laba atau rugi dari penjualan konsinyasi tidak dipisahkan dengan laba atau rugi dari penjualan biasa atau penjualan lainnya. Hal ini akan mengakibatkan pada akhir periode perusahaan tidak dapat mengetahui berapa laba atau rugi yang diperoleh dari penjualan konsinyasi dan berapa laba yang diperolah dari penjualan biasa atau penjualan lainnya. Untuk tujuan pengendalian intern sebaiknya perusahaan tidak menggunakan metode ini.

\section{Akuntansi Konsinyasi oleh Pengamanat (Consignor)}

Setiap transaksi yang berhubungan dengan penjualan konsinyasi baik menyangkut pendapatan maupun biaya dicatat dalam rekening barang konsinyasi atau consigment out. Pengamanat (consignor) mencatat/menjurnal pada saat:

a. Menitipkan barang ke komisioner (consignee) dan

b. Menerima laporan konsinyasi serta uang dari komisioner (consignee).

Transaksi yang berhubungan dengan pengiriman barang konsinyasi dan biaya-biaya penjualan konsinyasi akan didebit, misalnya:

a. Saat mengirimkan barang ke komisioner (rekening barang konsinyasi)

b. Biaya pengiriman barang ke komisioner

c. Biaya komisi

d. Biaya-biaya yang dikeluarkan oleh komisioner tetapi diganti oleh pengamanat.

Transaksi yang berhubungan dengan hasil penjualan barang konsinyasi dan pendapatan konsinyasi akan di kredit, yaitu:

a. Saat mencatat pendapatan konsinyasi

b. laba konsinyasi.

c. Saat menerima laporan tentang hasil penjualan barang konsinyasi (rekening barang konsinyasi) 


\section{Akuntansi Komnsinyasi oleh Komisioner (Consignee)}

Bagi Consignee setiap transaksi pendapatan yang berhubungan dengan penjualan konsinyasi dimasukkan ke dalam rekening barang komisi atau consignment in. Komisioner hanya membuat jurnal saat:
a. menjual barang konsinyasi,
b. mengeluarkan biaya-biaya yang berhubungan dengan konsinyasi
c. mencatat pendapatan komisi dan
d. pengiriman uang ke pengamanat (consignor)

Sesaat sebelum melaporkan ke pengamanat (consignor), komisioner terlebih dahulu menghitung pendapatan komisi. Kemungkinan-kemungkinan yang berhubungan Laporan Konsinyasi:

a. Komisioner dapat hanya mengirim laporan konsinyasi saja ke pengamanat, sedangkan uangnya dikirim beberapa waktu kemudian. Jadi saat mengirim laporan pada komisioner timbul utang pengamanat.

b. Komisioner bisa langsung mengirim laporan konsinyasi beserta uang ke pengamanat. Transaksi yang berhubungan dengan biaya-biaya penjualan konsinyasi, akan didebit, misalnya:

a) Biaya-biaya yang dikeluarkan komisioner tetapi akan diganti oleh pengamanat.

b) Pendapatan komisi yang belum diterima

c) Melaporkan penjualan konsinyasi kepada pengamanat

d) Membayar uang kepada pengamanat

\section{Syarat Penjualan Konsinyasi}

Menurut Afriyanto (2014), syarat-syarat penjualan konsinyasi biasanya diatur antara pengamanat dan komisioner dalam satu kontrak atau perjanjian konsinyasi, di mana dalam perjanjian ini tercantum beberapa ketentuan atau kesepakatan yang harus dijalankan selama pelaksanaan penjualan konsinyasi. Menurut Simamora (2005), sebelum pengamanat dan komisioner melakukan kegiatanya mereka menyusun suatu kontrak perjanjian atau persetujuan. Ketentuanketentuan dalam penjulan konsinyasi pada umumnya dinyatakan secara tertulis dan menekankan sifat hubungan kerjasama antara kedua bela pihak.

Menurut Hidayat (2012), dalam penyerahan barang atas dasar konsinyasi, harus disusun kontrak (persetujuan) tertulis yang menunjukkan sifat hubungan antara pihak yang menyerahkan dan yang menerima barang. Kontrak tertulis ini antara lain mencakup :

1. Syarat kredit yang harus diberikan oleh pihak komisioner kepada pelanggan.

2. Beban yang dikeluarkan oleh pihak komisioner harus diganti oleh pihak pengamanat.

3. Komisi atau laba yang harus diberikan kepada pihak komisiner.

4. Pengiriman uang dan penyelesaian keungan oleh pihak komisioner

5. Laporan yang harus dikirim oleh pihak komisioner.

\section{Pencatatan Penjualan Konsinyasi}

Menurut Jamiyla (2011), dalam prinsipnya pendapatan pada konsinyasi diakui saat penjualan terhadap barang-barang konsinyasi dilakukan oleh komisioner kepada pihak ketiga. Jika pengamanat membutuhkan laporan penjualan atas penjualan barang-barang konsinyasi, maka pencatatannya harus diselenggarakan terpisah dari transaksi penjualan reguler. Bagi pihak pengamanat, jika laba atas penjualan konsinyasi harus ditetapkan tersendiri, maka rekening barang-barang konsinyasi 
untuk masing-masing komisioner dibebani harga pokok barang yang dikirimkan kepada komisioner dan semua biaya yang berkaitan dengan konsinyasi.

Menurut Afriyanto (2014), ada dua metode yang dipakai untuk akuntansi penjualan konsinyasi baik oleh pengamanat maupun oleh komisioner :

1. Metode neto yaitu transaksi-transaksi konsinyasi dicatat secarah terpisah dari transaksitransaksi penjualan biasa (regular sales).

2. Metode bruto yaitu transaksi-transaksi konsinyasi dicatat secara tidak terpisah dari transaksitransaksi penjualan biasa.

Menurut Yendrawati (2008), berhubung penjualan konsinyasi melibatkan dua pihak yaitu pengamanat dan komisioner maka akuntansi juga diselenggarakan oleh pengamanat dan juga diselenggarakan oleh komisioner. Baik pengamanat maupun komisioner ada dua metode pacatatann akuntansi yang dapat digunakan :

1. Metode Terpisah (Neto)

Dalam metode terpisah laba atau rugi dari penjualan konsinyasi disajikan secara terpisah dengan laba atau rugi penjualan biasa atau penjualan lainnya.

Hal ini dilakukan dengan tujuan agar pada akhir periode dapat diketahui berapa laba atau rugi yang diperoleh dari penjualan konsinyasi dan berapa laba atau rugi yang diperoleh dari penjualan lainnya.

2. Metode Tidak Terpisah (Bruto)

Dalam metode tidak terpisah laba atau rugi dari penjualan konsinyasi tidak dipisahkan dengan laba atau rugi dari penjualan biasa atau penjualan lainnya. Hal ini akan mengakibatkan pada akhir periode perusahaan tidak dapat mengetahui berapa laba atau rugi yang diperoleh dari penjualan konsinyasi dan berapa laba yang diperolah dari penjualan biasa atau penjualan lainnya. Untuk tujuan pengendalian intern sebaiknya perusahaan tidak menggunakan metode ini.

\section{METODE PENELITIAN}

\section{Desain Penelitian}

Penelitian ini menggunakan metode analisis deskriptif yaitu penerapan akuntansi konsinyasi pada Toko Asrif Jati Curup dengan menggunakan metode terpisah dan tidak terpisah. Dalam akuntansi konsinyasi ini pihak toko Asrif jati bertindak sebagai consigneel pihak yang menerima titipan barang dari PT Jati Jepara. Pada penelitian ini dianalisis bagaimana jurnal dan perhitungan yang dilakukan toko Asrif Jati dengan menggunakan metode terpisah dan tidak terpisah Penelitian dilakukan dengan mengadakan observasi langsung dan wawancara guna mendapatkan data yang diperlukan.

\section{Populasi \& Sampel}

Populasi pada penelitian ini adalah seluruh barang komisi yang diterima oleh Toko Asrif Jati curup dari PT Jati Jepara. Sedangkan sampel pada penelitian ini adalah barang konsinyasi yang diterima oleh Toko Asrif Jati dari PT Jati Jepara untuk periode pengiriman Januari sampai dengan Maret 2020. 


\section{Teknik Pengumpulan Data}

1. Studi Literatur

Menurut Sugiyono (2012), Studi pustaka adalah referensi serta literatur ilmiah lainnya yang berkaitan dengan budaya, nilai dan norma yang berkembang pada situasi sosial yang diteliti, selain itu studi kepustakaan sangat penting dalam melakukan penelitian, hal ini dikarenakan penelitian tidak akan lepas dari literatur-literatur ilmiah. Studi literatur dengan membaca teoriteori yang berhubungan dengan penjualan konsinyasi untuk dijadikan landasan teori dan penelitian terdahulu guna dijadikan perbandingan dalam pembahasan penelitian.

2. Studi Lapangan

Menurut Imam Ghozali (2013), Studi lapangan adalah metode pembelajaran melalui pengumpulan data secara langsung dengan pengamatan, wawancara, mencatat, atau mengajukan pertanyaan-pertanyan. Studi lapangan dilakukan dengan cara berikut:

a. Pengamatan

Menurut Sutrisno Hadi dalam Sugiyono (2013:145) mengemukakan bahwa, observasi merupakan suatu proses yang kompleks, suatu proses yang tersusun dari berbagai proses biologis dan psikhologis. Observasi dilakukan penulis dengan mendatangi langsung objek penelitian yaitu Toko Asrif Jati Curup guna mengetahui kegiatan operasional perusahaan.

b. Wawancara (interview)

Menurut Esterberg dalam Sugiyono (2013:231), Wawancara merupakan pertemuan dua orang untuk bertukar informasi dan ide melalui tanya jawab, sehingga dapat dikontruksikan makna dalam suatu topik tertentu. Wawancara dilakukan untuk mendapatkan data-data baik yang bersifat kualitatif maupun kuantitatif yang ada pada Toko Asrif Jati Curup.

c. Dokumentasi

Menurut Sugiyono (2013;240), Dokumen merupakan catata peristiwa yang sudah berlalu. Dokumen bisa berbentuk tulisan, gambar atau karya-karya monumental dari seseorang. Dokumentasi dalam penelitian ini digunakan untuk mengambil referensi baik dalam bentuk penelitian terdahulu ataupun buku-buku akuntansi keuangan yang membahas mengenai penjualan konsinyasi.

\section{Teknik Analisis Data}

\section{Analisis Data}

Dalam analisis data dilakukan pengumpulan data yang diperoleh, disusun, dianalisis, sehingga dapat memberikan informasi yang jelas tentang akuntansi konsinyasi. Data yang dkumpulkan berupa data pengiriman barang komisi, biaya angkut dan jumlah penjualan barang komisi.

2. Perhitungan akuntansi konsinyasi

Dalam perhitungan akuntansi konsinyasi penulis melakukan perhitungan berdasarkan akuntansi konsinyasi dengan pencatatan secara terpisah dan tidak terpisah sebagai berikut: 
Tabel 3

Akuntansi Konsinyasi Untuk Consignee

\begin{tabular}{|c|c|c|c|c|c|c|}
\hline \multirow[b]{2}{*}{ Transaksi } & \multicolumn{3}{|c|}{ Pencatatan Secara Terpisah } & \multicolumn{3}{|c|}{ Pencatatan secara tak terpisah } \\
\hline & Uraian & Debet & Kredit & Uraian & Debet & Kredit \\
\hline $\begin{array}{l}\text { Penerimaan } \\
\text { konsinyasi }\end{array}$ & Tidak dijurnal & - & - & Tidak dijurnal & & \\
\hline $\begin{array}{l}\text { Penjualan barang } \\
\text { komisi }\end{array}$ & $\begin{array}{l}\text { Kas } \\
\text { Brg Komisi }\end{array}$ & $\mathrm{XX}$ & $\mathrm{XX}$ & $\begin{array}{l}\text { Kas } \\
\quad \text { Penjualan } \\
\text { Pembelian/HPP } \\
\text { Utang Kpd Consignor }\end{array}$ & $\begin{array}{l}\text { XX } \\
\text { XX }\end{array}$ & XX \\
\hline $\begin{array}{l}\text { Pembayaran ongkos } \\
\text { angkut }\end{array}$ & $\begin{array}{l}\text { Barang komisi } \\
\text { Kas }\end{array}$ & $\mathrm{XX}$ & $\mathrm{XX}$ & $\begin{array}{l}\text { Utang kpd Consignor } \\
\text { Kas }\end{array}$ & $\mathrm{XX}$ & $\mathrm{XX}$ \\
\hline Perhitungan komisi & $\begin{array}{l}\text { Barang Komisi } \\
\text { Kas }\end{array}$ & $\mathrm{XX}$ & $\mathrm{XX}$ & Tidak dijurnal & & \\
\hline 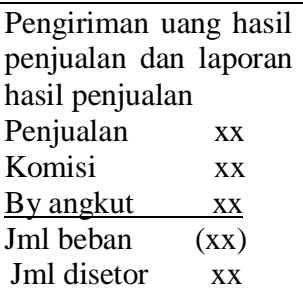 & $\begin{array}{l}\text { Barang komisi } \\
\text { Kas }\end{array}$ & $\mathrm{XX}$ & $\mathrm{XX}$ & $\begin{array}{ccc}\text { Utang } & \text { kpd } & \text { consignor } \\
\text { Kas } & & \end{array}$ & $\mathrm{XX}$ & $\mathrm{XX}$ \\
\hline
\end{tabular}

Sumber : Evi Maria, 2011

\section{HASIL DAN PEMBAHASAN}

\section{Analisis Data}

Data yang digunakan pada penelitian ini adalah data mengenai jumlah unit, harga jual per unit, biaya angkut dan biaya komisi untuk pengiriman barang yang diterima Toko Asrif Jati dari PT Jati Jepara. Berikut data yang digunakan pada penelitian ini:

\section{Tabel 4}

Biaya angkut, harga jual dan jumlah unit yang dikirimkan bulan Januari - Maret 2020

\begin{tabular}{|c|c|c|c|}
\hline Keterangan & Januari & Februari & Maret \\
\hline Jumlah Unit & $\begin{array}{l}30 \text { unit } \\
20 \text { Unit Kursi tamu } \\
10 \text { Unit Meja } \\
\text { Makan }\end{array}$ & $\begin{array}{l}32 \text { Unit } \\
10 \text { Unit Meja Rias } \\
12 \text { Unit Lemari } \\
\text { Kristal } 3 \text { pintu } \\
10 \text { Unit jam jati }\end{array}$ & $\begin{array}{l}31 \text { Unit } \\
9 \text { Unit Hiasan } \\
\text { dinding } \\
13 \text { Unit Lemari } \\
\text { sudut kristal } \\
9 \text { Unit Ayunan jati }\end{array}$ \\
\hline Harga/Unit & $\begin{array}{l}\text { Kursi Tamu@Rp. } \\
4.500 .000 \\
\text { Meja makan @ Rp. } \\
5.200 .000\end{array}$ & 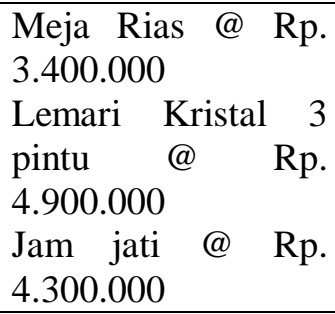 & $\begin{array}{l}\text { Hiasan dinding @ } \\
\text { Rp.2.900.000 } \\
\text { Lemai sudut kristal } \\
@ \text { Rp.2.200.000 } \\
\text { Ayunan Jati@ @p. } \\
3.600 .000\end{array}$ \\
\hline Biaya Angkut & Rp. 1.500.000 & Rp.1.500.000 & Rp. 1.500.000 \\
\hline Total & Rp. 143.500.000 & Rp. 137.300.000 & Rp. 88.600.000 \\
\hline
\end{tabular}

Sumber : Toko Asrif Jati, 2020 
Dengan menggunakan data pada tabel 4.1, maka dilakukan pencatatan untuk penjualan konsinyasi untuk periode bulan januari s/d maret 2020.

\section{Akuntansi Penjualan Konsinyasi Bulan Januari}

Dari pengiriman barang bulan Januari sebanyak 30 Unit yang terdiri dari 20 unit kursi tamu dan 10 unit meja makan dimana komisi untuk Toko Asrif Jati sebesar 10\% dari total penjualan, maka jumlah unit yan terjual adalah sebanyak 11 unit dengan rincian 7 unit kursi tamu @ Rp. 5.000.000 dan meja makan 4 unit @ Rp. 5.750.000. Maka total penjualan untuk bulan Januari adalah Rp. 58.000.000. Berikut tabel penjualan untuk bulan Januari tahun 2020.

\section{Tabel 5}

Penjualan Bulan Januari Tahun 2020

\begin{tabular}{|l|l|l|l|c|}
\hline \multicolumn{1}{|c|}{ Keterangan } & $\begin{array}{c}\text { Jumlah } \\
\text { Unit }\end{array}$ & \multicolumn{1}{|c|}{ Harga/Unit } & \multicolumn{1}{c|}{ HPP/unit } & Total \\
\hline Meja Makan & 4 Unit & Rp. 5.750.000 & Rp. 5.200.000 & Rp. 23.000.000 \\
\hline Kursi Tamu & 7 Unit & Rp. 5.000.000 & Rp. 4.500.000 & Rp. 35.000.000 \\
\hline Total & & & Rp.52.300.000 & Rp. 58.000.000 \\
\hline
\end{tabular}

Sumber : Toko Asrif Jati, 2020

Berdasarkan data penjualan bulan Januari tersebut, maka dibuat pencatatan penjualan konsinyasi untuk Toko Asrif Jati (Consignee).

Tabel 6

Akuntansi Penjualan Konsinyasi Bulan Januari 2020(dalam ribuan rupiah)

\begin{tabular}{|c|c|c|c|c|c|c|}
\hline \multirow[b]{2}{*}{ Transaksi } & \multicolumn{3}{|c|}{ Pencatatan Secara Terpisah } & \multicolumn{3}{|c|}{ Pencatatan secara tak terpisah } \\
\hline & Uraian & Debet & Kredit & Uraian & Debet & Kredit \\
\hline $\begin{array}{ll}\text { Penerimaan } & \text { barang } \\
\text { konsinyasi } & \\
\end{array}$ & $\begin{array}{l}\text { Tidak } \\
\text { dijurnal }\end{array}$ & - & - & Tidak dijurnal & & \\
\hline $\begin{array}{l}\text { Penjualan barang } \\
\text { komisi }\end{array}$ & $\begin{array}{l}\text { Kas } \\
\text { Brg } \\
\text { Komisi }\end{array}$ & 58.000 & 58.000 & $\begin{array}{l}\text { Kas } \\
\quad \text { Penjualan } \\
\text { Pembelian/HPP } \\
\quad \text { Utang } \\
\text { Consignor }\end{array}$ & $\begin{array}{l}58.000 \\
52.300\end{array}$ & 58.000 \\
\hline $\begin{array}{l}\text { Pembayaran ongkos } \\
\text { angkut }\end{array}$ & $\begin{array}{l}\text { Barang } \\
\text { komisi } \\
\text { Kas }\end{array}$ & 1.500 & 1.500 & $\begin{array}{l}\text { Utang kpd Consignor } \\
\text { Kas }\end{array}$ & 52.300 & 52.300 \\
\hline $\begin{array}{l}\text { Perhitungan komisi } \\
(10 \%)\end{array}$ & $\begin{array}{l}\text { Barang } \\
\text { Komisi } \\
\text { Pendapatan } \\
\text { Komisi } \\
\end{array}$ & 5.800 & 5.800 & Tidak dijurnal & & \\
\hline $\begin{array}{lr}\text { Pengiriman } & \text { uang } \\
\text { hasil penjualan dan } \\
\text { laporan } & \text { hasil } \\
\text { penjualan } & \\
\text { Penjualan } & 58.000 \\
\text { Komisi } & (5.800) \\
\text { By angkut } & (1.500) \\
\end{array}$ & $\begin{array}{c}\text { Barang } \\
\text { komisi } \\
\text { Kas }\end{array}$ & 50.700 & 50.700 & $\begin{array}{l}\text { Utang kpd consignor } \\
\text { Kas }\end{array}$ & 50.700 & 50.700 \\
\hline
\end{tabular}




\begin{tabular}{|cc|l|l|l|l|l|}
\hline Jml beban & $(7.300)$ \\
Jml disetor 50.700 & & & & & & \\
\hline
\end{tabular}

Sumber : Hasil Analisis, 2020

\section{Akuntansi Penjualan Konsinyasi Bulan Februari}

Untuk penjualan bulan Februari tahun 2018 dari 32 unit yang dikirim yang terjual sebanyak 9 unit yang terdiri dari meja rias 3 unit @ Rp. 3.800.000, 4 unit jam jati @ Rp. 4.700.000, lemari kristal 2 unit@ Rp.5.500.000, kursi tamu 3 unit @ Rp. 5000.000 (Sisa persediaan bulan Januari).

\section{Tabel 7}

Penjualan Bulan Februari Tahun 2020

\begin{tabular}{|c|c|c|c|c|}
\hline Keterangan & $\begin{array}{c}\text { Jumlah } \\
\text { Unit }\end{array}$ & Harga/Unit & HPP/unit & Total \\
\hline Meja Rias & 3 & Rp. 3.800.000 & Rp. 3.400.000 & Rp. 11.400 .000 \\
\hline Jam Jati & 4 & Rp. 4.800.000 & Rp. 4.300.000 & Rp. 19.200 .000 \\
\hline $\begin{array}{c}\text { Lemari } \\
\text { Kristal }\end{array}$ & 2 & Rp. 5.500.000 & Rp. 4.900.000 & Rp. 11.000 .000 \\
\hline Kursi tamu & 3 & Rp. 5.000.000 & Rp.4.500.000 & Rp. 15.000.000 \\
\hline Total & 12 & & Rp.50.700.000 & Rp. 56.600.000 \\
\hline
\end{tabular}

Sumber : Toko Asrif Jati, 2020

Berdasarkan data diatas, maka pencatatan konsinyasi untuk toko Asrif Jati adalah sebagai berikut :

\section{Tabel 8}

Akuntansi Penjualan Konsinyasi Bulan Februari 2020 (dalam ribuan rupiah)

\begin{tabular}{|c|c|c|c|c|c|c|}
\hline \multirow[b]{2}{*}{ Transaksi } & \multicolumn{3}{|c|}{ Pencatatan Secara Terpisah } & \multicolumn{3}{|c|}{ Pencatatan secara tak terpisah } \\
\hline & Uraian & Debet & Kredit & Uraian & Debet & Kredit \\
\hline $\begin{array}{l}\text { Penerimaan } \\
\text { konsinyasi }\end{array}$ & $\begin{array}{l}\text { Tidak } \\
\text { dijurnal }\end{array}$ & - & - & Tidak dijurnal & & \\
\hline $\begin{array}{l}\text { Penjualan barang } \\
\text { komisi }\end{array}$ & $\begin{array}{l}\text { Kas } \\
\text { Brg } \\
\text { Komisi }\end{array}$ & 56.600 & 56.600 & $\begin{array}{l}\text { Kas } \\
\quad \text { Penjualan } \\
\text { Pembelian/HPP } \\
\quad \text { Utang } \\
\text { Consignor }\end{array}$ & $\begin{array}{l}56.600 \\
50.700\end{array}$ & 56.600 \\
\hline $\begin{array}{l}\text { Pembayaran ongkos } \\
\text { angkut }\end{array}$ & $\begin{array}{c}\text { Barang } \\
\text { komisi } \\
\text { Kas } \\
\end{array}$ & 1.500 & 1.500 & $\begin{array}{l}\text { Utang kpd Consignor } \\
\text { Kas }\end{array}$ & 1.500 & 1.500 \\
\hline $\begin{array}{l}\text { Perhitungan komisi } \\
(10 \%)\end{array}$ & $\begin{array}{l}\text { Barang } \\
\text { Komisi } \\
\text { Pendapata } \\
\text { n komisi }\end{array}$ & 5.660 & 5.660 & Tidak dijurnal & & \\
\hline $\begin{array}{l}\text { Pengiriman uang hasil } \\
\text { penjualan dan laporan } \\
\text { hasil penjualan }\end{array}$ & $\begin{array}{l}\text { Barang } \\
\text { komisi } \\
\text { Kas }\end{array}$ & 49.440 & 49.440 & $\begin{array}{l}\text { Utang kpd consignor } \\
\text { Kas }\end{array}$ & 49.440 & 49.440 \\
\hline
\end{tabular}




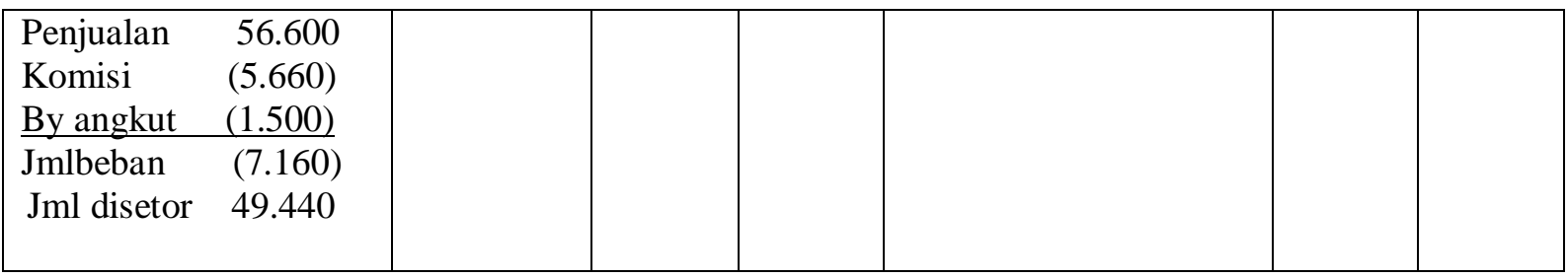

Sumber : Hasil Analisis, 2020

Dari tabel diatas dapat dilihat Komisi yang diterima oleh Toko Asrif Jati untuk penjualan pada bulan Maret adalah sebesar Rp.5.660.000, dari total penjualan sebesar Rp. 56.600.000.

\section{Akuntansi Penjualan Konsinyasi Bulan Maret}

Berikutnya adalah penjualan bulan Maret dengan jumlah pengiriman sebanyak 31 unit dengan rincian barang yang terjual adalah sebagai berikut : Hiasan dinding 5 unit @ Rp. 3.200.000, Lemari sudut kristal 5 unit @ Rp.2.500.000, Ayunan jati 3 unit @ Rp.4.000.000, kursi tamu 6 unit @ Rp. 5.000.000, Meja makan 3 unit @ Rp. 5.750.000, Meja rias 3 unit @ Rp. 3.800.000, Lemari Kristal 2 unit @ Rp.5.500.000.

\section{Tabel 9}

Penjualan Bulan Maret Tahun 2020

\begin{tabular}{|c|c|c|c|c|}
\hline Keterangan & $\begin{array}{c}\text { Jumlah } \\
\text { Unit }\end{array}$ & Harga/Unit & HPP/unit & Total \\
\hline $\begin{array}{l}\text { Hiasan } \\
\text { dinding }\end{array}$ & 5 & Rp. 3.200.000 & Rp. 2.900 .000 & Rp. 16.000 .000 \\
\hline $\begin{array}{l}\text { Lemari } \\
\text { sudut Kristal }\end{array}$ & 5 & Rp. 2.500.000 & Rp. 2.200.000 & Rp. 12.500 .000 \\
\hline Ayunan Jati & 3 & Rp. 4.000.000 & Rp. 3.600.000 & Rp. 12.000 .000 \\
\hline Kursi tamu & 6 & Rp. 5.000.000 & Rp. 4.500.000 & Rp. 30.000 .000 \\
\hline Meja makan & 3 & Rp. 5.750.000 & Rp. 5.200.000 & Rp. 17.250.000 \\
\hline Meja rias & 3 & Rp. 3.800.000 & Rp. 3.400.000 & Rp. 11.400 .000 \\
\hline $\begin{array}{l}\text { Lemari } \\
\text { Kristal }\end{array}$ & 2 & Rp. 5.500.000 & Rp. 4.900 .000 & Rp. 11.000 .000 \\
\hline Jam jati & 1 & Rp. 4.800 .000 & Rp. 4.300 .000 & Rp. 4.800 .000 \\
\hline Total & & & Rp. 103.200.000 & Rp. 114.950 .000 \\
\hline
\end{tabular}

Sumber : Toko Asrif Jati, 2020

Berdasarkan penjualan Maret tahun 2020, maka akuntansi penjualan konsinyasi dapat dilihat pada tabel berikut ini :

Tabel 10

Akuntani Penjualan Konsinyasi Bulan Maret 2020 (dalam ribuan rupiah)

\begin{tabular}{|c|c|c|c|c|c|c|}
\hline \multirow[b]{2}{*}{ Transaksi } & \multicolumn{3}{|c|}{ Pencatatan Secara Terpisah } & \multicolumn{3}{|c|}{ Pencatatan secara tak terpisah } \\
\hline & Uraian & Debet & Kredit & Uraian & Debet & Kredit \\
\hline $\begin{array}{l}\text { Penerimaan barang } \\
\text { konsinyasi }\end{array}$ & Tidak dijurnal & 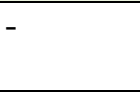 & - & $\begin{array}{l}\text { Tidak } \\
\text { dijurnal }\end{array}$ & & \\
\hline $\begin{array}{l}\text { Penjualan barang } \\
\text { komisi }\end{array}$ & $\begin{array}{l}\text { Kas } \\
\text { Brg Komisi }\end{array}$ & 114.950 & 114.950 & $\begin{array}{l}\text { Kas } \\
\quad \text { Penjualan } \\
\text { Pembelian/H } \\
\text { PP }\end{array}$ & $\begin{array}{l}114.950 \\
103.200\end{array}$ & $\begin{array}{l}114.950 \\
103.200\end{array}$ \\
\hline
\end{tabular}




\begin{tabular}{|l|l|l|l|l|l|l|}
\hline & & & & $\begin{array}{l}\text { Utang Kpd } \\
\text { Consignor }\end{array}$ & & \\
\hline $\begin{array}{l}\text { Pembayaran ongkos } \\
\text { angkut }\end{array}$ & $\begin{array}{l}\text { Barang komisi } \\
\text { Kas }\end{array}$ & 1.500 & 1.500 & $\begin{array}{l}\text { Utang kpd } \\
\text { Consignor } \\
\text { Kas }\end{array}$ & 1.500 & 1.500 \\
\hline $\begin{array}{l}\text { Perhitungan komisi } \\
(10 \%)\end{array}$ & $\begin{array}{l}\text { Barang Komisi } \\
\text { Pendapatan } \\
\text { Komisi }\end{array}$ & 11.495 & 11.495 & $\begin{array}{l}\text { Tidak } \\
\text { dijurnal }\end{array}$ & & \\
\hline $\begin{array}{l}\text { Pengiriman uang hasil } \\
\text { penjualan dan laporan } \\
\text { hasil penjualan }\end{array}$ & $\begin{array}{l}\text { Barang komisi } \\
\text { Kas }\end{array}$ & 101.955 & 101.955 & $\begin{array}{l}\text { Utang kpd } \\
\text { consignor } \\
\text { Kas }\end{array}$ & 101.955 & 101.955 \\
$\begin{array}{l}\text { Penjualan 114.950 } \\
\text { Komisi (11.495) } \\
\text { By angkut (1.500) } \\
\text { Jml beban (12.995) }\end{array}$ & & & & & & \\
Jml disetor 101.955 & & & & & & \\
\hline
\end{tabular}

Sumber : Hasil Analisis, 2020

Berdasarkan tabel penjualan pada bulan Maret, dapat dilihat jika total penjualan adalah sebesar Rp. 114. 950.000 sedangkan jumlah yang disetor kepada PT. Jati Jepara adalah sebesar Rp. 101.955.000. Untuk dapat melihat penjualan konsinyasi selama bulan Januari s/d Maret tahun 2020, maka dijelaskan dalam tabel berikut:

\section{Tabel 11}

Penjualan Konsinyasi Bulan Januari s/d Maret Toko Asrif Jati

\begin{tabular}{|c|c|c|c|}
\hline Keterangan & Penjualan & Jumlah disetor & Komisi \\
\hline Januari & Rp. 50.000.000 & Rp. 50.700.000 & Rp. 5.800.000 \\
\hline Februari & Rp. 56.600.000 & Rp. 49.440.000 & Rp. 5.660.000 \\
\hline Maret & Rp. 114.950.000 & Rp. 101.955.000 & Rp. 11.495.000 \\
\hline
\end{tabular}

Sumber : Hasil Analisis, 2020

Dari tabel diatas dapat dilihat tingginya penjualan pada bulam Maret yaitu sebesar Rp. 114.950.000 hal ini dikarenakan meningkatnya kebutuhan masyarakat akan meubel jati terutama menjelang hari raya Idul Fitri.

\section{KESIMPULAN DAN SARAN}

\section{Kesimpulan}

Berdasarkan hasil analisis penjualan konsinyasi dengan menggunakan metode terpisah dan tidak terpisah pada Toko Asrif Jati Curup maka dapat diambil kesimpulan sebagai berikut:

1. Penjualan bulan Januari sebesar Rp. 58.000.000 dengan komisi untuk toko Asrif Jati sebagai consignee sebesar Rp. 5.800.000 dan jumlah uang yang disetor kepada PT Jati Jepara adalah sebesar Rp. 50.700.000

2. Penjualan bulan Februari sebesar Rp. 56.600.000 dengan komisi untuk toko Asrif Jati sebagai consignee sebesar Rp. 5.660.000 dan jumlah uang yang disetor kepada PT Jati Jepara adalah sebesar Rp. 50.700.000 
3. Penjualan bulan Maret sebesar Rp. 114.950.000 dengan komisi untuk toko Asrif Jati sebagai consignee sebesar Rp. 11.495.000 dan jumlah uang yang disetor kepada PT Jati Jepara adalah sebesar Rp. 103.200.000

\section{Saran}

Berdasarkan kesimpulan diatas maka pada penelitian ini penulis memberikan saran sebagai berikut:

1. Untuk memudahkan dalam pencatatan dan pengecekan persediaan sebaiknya Toko Asrif Jati Curup melakukan pencatatan persediaan barang setiap bulannya, mengingat tidak semua barang yang dikirim habis terjual.

2. Agar pencatatan untuk penjualan konsinyasi dilakukan secara tepat sesuai dengan standar akuntansi supaya tidak terjadi kesalahan dalam perhitungan jumlah penjualan dan jumlah yang harus disetor karena harga jual dari barang konsinyasi tersebut cukup mahal.

3. Supaya antara pihak Toko Asrif Jati Curup sebagai Consignee dan PT Jati Jepara Sebagai Consignor melakukan kesepakatan yang jelas terutama mengenai komisi dan barang-barang yang belum laku terjual.

\section{DAFTAR PUSTAKA}

Abdul Halim,2015. Akuntansi Keuangan Lanjutan,Edisi Pertama, Mitra Wacana Media Jakarta

Arifin Sabeni, 2012. Ikhtisar Teori dan Soal Jawab Akuntansi Lanjutan, Buku 1, BPFE, Yogyakarta

-- Ikhtisar Teori dan Soal Jawab Akuntansi Lanjutan, Buku 2, BPFE, Yogyakarta

2012. Pokok-pokok Akuntansi Keuangan Lanjutan, Liberty Yogyakarta

Evi Maria, 2011. Akuntansi Lanjutan, Edisi Pertama, Cetakan Pertama,Penerbit Gava Media Yogyakarta

Ghozali, Imam. 2013. Aplikasi Analisis Multivariate Dengan Program SPSS. Semarang :Badan Penerbit Universitas Diponegoro

Sugiyono. 2010. Metode Penelitian Pendidikan "Pendekatan Kuantitatif, Kualitatif, dan $R$ \& D". Bandung : Alfabeta.

Suparwoto, L. 2014. Akuntansi Keuangan Lanjutan. Edisi 3, BPFE Yogyakarta

Yunus, H dan Harnanto, 2013. Akuntansi Keuangan Lanjutan. Edisi 3, BPFE, Yogyakarta.

Tri Rahma Handayani, Rande Samben, Salmah Pattisahusiwa.2018.Analisis Penjualan Barang Konsinyasi Pada Coconut Mart. Jurnal Ilmu Akuntansi Mulawarman Volume 3 No.1 Tahun 2018.

Aas Rianti Ningrum. 2018.Analisis Metode Penjualan Konsinyasi Pada KUD Tani Wilis Sendang. Jurnal SIMKI Ekonomi Universitas Nusantara PGRI Kediri Volume 2 N0. 03 Tahun 2018.

Cici Tria Fauziah.2016.Analisis Penerapan Akuntansi Penjualan Konsinyasi Pada PT Surya Sumatera II Pasir Pengaraian.Jurnal Mahasiswa Fakultas Prodi Akuntansi Universitas Pengaraian Volume 2 No. 1 Tahun 2016. 